\title{
Guidelines
}

European

Thyroid Journal
Eur Thyroid J 2013;2:215-228

DOI: $10.1159 / 000356507$
Received: September 26, 2013

Accepted: October 7, 2013

Published online: November 27, 2013

\section{ETA Guideline: Management of Subclinical Hypothyroidism}

\author{
Simon H.S. Pearce ${ }^{a, b}$ Georg Brabant ${ }^{c}$ Leonidas H. Duntas ${ }^{d}$ Fabio Monzani ${ }^{e}$ \\ Robin P. Peeters ${ }^{f}$ Salman Razvia, Jean-Louis Wemeau ${ }^{\text {h }}$ \\ anstitute of Genetic Medicine, Newcastle University, and ${ }^{\text {b }}$ Royal Victoria Infirmary, Newcastle upon Tyne, UK;

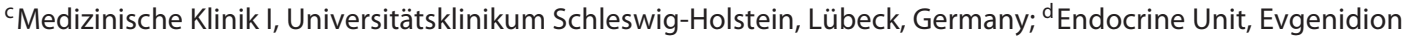

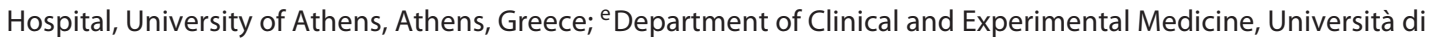 \\ Pisa, Pisa, Italy; ${ }^{\mathrm{f}}$ Rotterdam Thyroid Center, Department of Internal Medicine, Erasmus Medical Center, Rotterdam, \\ The Netherlands; ${ }^{9}$ Queen Elizabeth Hospital, Gateshead, UK; ${ }^{\mathrm{h}}$ Clinique Endocrinologique Marc Linquette, CHU, Lille, \\ France
}

\section{Key Words}

Subclinical hypothyroidism · Thyrotropin · L-Thyroxine .

Vascular risk · Cognition · Management

\begin{abstract}
Subclinical hypothyroidism ( $\mathrm{SCH}$ ) should be considered in two categories according to the elevation in serum thyroidstimulating hormone (TSH) level: mildly increased TSH levels (4.0-10.0 mU/l) and more severely increased TSH value ( $>10$ $\mathrm{mU} / \mathrm{l})$. An initially raised serum $\mathrm{TSH}$, with $\mathrm{FT}_{4}$ within reference range, should be investigated with a repeat measurement of both serum $\mathrm{TSH}_{\mathrm{H}}$ and $\mathrm{FT}_{4}$, along with thyroid peroxidase antibodies, preferably after a 2- to 3-month interval. Even in the absence of symptoms, replacement therapy with L-thyroxine is recommended for younger patients $(<65-70$ years) with serum TSH $>10 \mathrm{mU} / \mathrm{l}$. In younger $\mathrm{SCH}$ patients (serum TSH $<10 \mathrm{mU} / \mathrm{l}$ ) with symptoms suggestive of hypothyroidism, a trial of L-thyroxine replacement therapy should be considered. For such patients who have been started on L-thyroxine for symptoms attributed to $\mathrm{SCH}$, response to treatment should be reviewed 3 or 4 months after a serum TSH within reference range is reached. If there is no improvement in symptoms, L-thyroxine therapy should generally be
\end{abstract}

stopped. Age-specific local reference ranges for serum TSH should be considered in order to establish a diagnosis of $\mathrm{SCH}$ in older people. The oldest old subjects (>80-85 years) with elevated serum TSH $\leq 10 \mathrm{mU} / \mathrm{l}$ should be carefully followed with a wait-and-see strategy, generally avoiding hormonal treatment. If the decision is to treat $\mathrm{SCH}$, then oral L-thyroxine, administered daily, is the treatment of choice. The serum TSH should be re-checked 2 months after starting L-thyroxine therapy, and dosage adjustments made accordingly. The aim for most adults should be to reach a stable serum TSH in the lower half of the reference range $(0.4-2.5 \mathrm{mU} / \mathrm{l})$. Once patients with $\mathrm{SCH}$ are commenced on L-thyroxine treatment, then serum TSH should be monitored at least annually thereafter.

(c) 2013 European Thyroid Association Published by S. Karger AG, Basel

\section{Introduction}

Subclinical hypothyroidism ( $\mathrm{SCH})$ is defined as a state of increased serum thyroid-stimulating hormone (TSH) levels, with circulating thyroxine $\left(\mathrm{T}_{4}\right)$ and tri-iodothyronine $\left(\mathrm{T}_{3}\right)$ concentrations within the population reference

\begin{tabular}{ll}
\hline KARGER & $\begin{array}{l}\odot 2013 \text { European Thyroid Association } \\
\text { Published by S. Karger AG, Basel }\end{array}$ \\
E-Mail karger@karger.com & $2235-0640 / 13 / 0024-0215 \$ 38.00 / 0$ \\
www.karger.com/etj &
\end{tabular}

Prof. Simon Pearce

Newcastle University Institute of Genetic Medicine

International Centre for Life, Central Parkway

Newcastle upon Tyne NE1 3BZ (UK)

E-Mail simon.pearce@ncl.ac.uk 
Fig. 1. Suggested management algorithm. Initial management of persistent subclinical hypothyroidism in non-pregnant adults: persistent subclinical hypothyroidism describes patients with elevated serum $\mathrm{TSH}$ and within reference range serum $\mathrm{FT}_{4}$ on two occasions separated by at least 3 months. This algorithm is meant as a guide and clinicians are expected to use their discretion and judgement in interpreting the age threshold around 70 years. * Depending on circumstances, individuals with goitre, dyslipidaemia, and diabetes may also be considered for treatment, along with those with planning pregnancy in the near future.

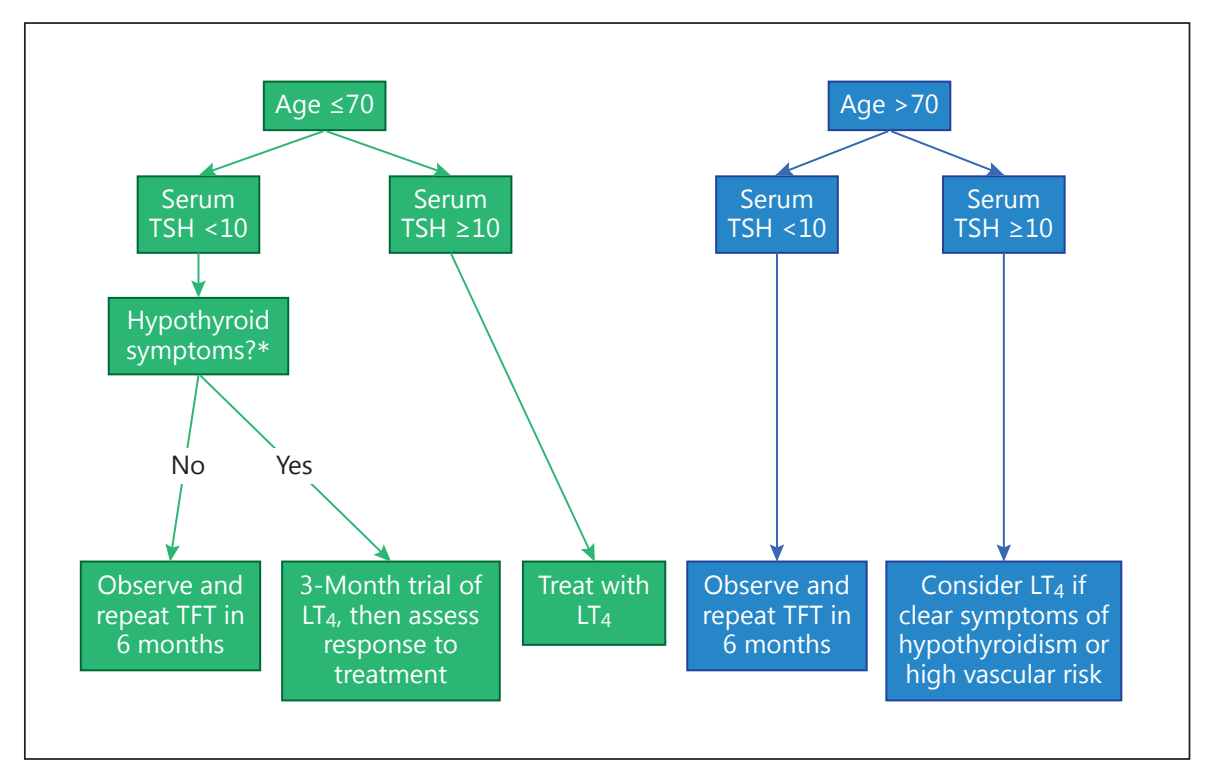

range. The incidence of SCH varies between 4 and 10\% depending upon the gender, age and population studied $[1,2]$. The consequences of SCH are variable at several levels and may depend on the duration and the degree of elevation of the serum TSH. However, a number of important questions about $\mathrm{SCH}$ remain, including whether it increases cardiovascular (CV) risk or mortality, whether it negatively influences metabolic parameters and whether it should be treated with L-thyroxine [3].

These open questions have prompted the European Thyroid Association (ETA) to form a task force with the aim of drawing up guidelines on the management of $\mathrm{SCH}$ in adults. A specific guideline on the management of $\mathrm{SCH}$ in children and in pregnancy will be prepared separately and these subjects are not covered in this guidance. Similarly, interpretation of elevated serum TSH while taking amiodarone is not covered in this guideline. Population screening for hypothyroidism was also considered a separate issue and is not covered by this guideline.

\section{Methods}

The Executive Committee of the ETA and the Guideline Board nominated a Task Force for the development of guidelines on the management of SCH. The Task Force had no commercial support and the members declared no conflict of interest. A list of all pertinent topics related to $\mathrm{SCH}$ was created and the members proceeded to a complete review of the literature, carrying out a systematic PubMed and Medline search for original and review articles published from 1970 through March 2013. For our Medline search, we entered in various combinations the terms thyrotropin (TSH), L-thyroxine, SCH, goitre, replacement therapy, CV risk, heart, dyslipidaemia, diabetes, obesity, mental health, quality of life, drugs. The guidelines were constructed based on the best scientific evidence and the skills of the Task Force, and where available data derived from randomised clinical trials rather than from observational studies has been selected. For recommendations, the GRADE system is employed which has recently been applied to other guidelines issued by the ETA and American Thyroid Association, this therefore enables alignment of part of the recommendations with those of other guidelines $[4,5]$. The quality of the literature concerning each aspect of the statement was graded as high (randomised controlled trial (RCT) evidence - level 1); moderate (intervention short of RCT or large observational studies level 2), or low quality (case series, case reports, expert opinion level 3) using modified GRADE criteria $[4,5]$. The strength of each statement was classified as strong ( $\mathrm{S}$ - a recommendation) or weak (W - a suggestion), depending upon the clinical significance and weight of opinion favouring the statement. Strong recommendations are clinically important best practice and will be applied to most patients in most circumstances, whereas weak statements should be considered by the clinician and will be applicable best practice only to certain patients or in certain circumstances (fig. 1).

\section{Diagnosis of Subclinical Hypothyroidism}

\section{Investigation of Raised Serum TSH}

The population prevalence of SCH amounts to approximately $5-10 \%$, being more frequent in women and with increasing prevalence with advancing age $[1,2,6-8]$. $\mathrm{SCH}$ is also more frequent in individuals of white Caucasian origin and in iodine-sufficient regions $[6,8]$. SCH is 
generally classified in two categories according to serum TSH level: mildly increased TSH levels (4.0-10.0 mU/l) and more severely increased serum TSH concentrations $(>10.0 \mathrm{mU} / \mathrm{l})[9,10]$. The former, milder condition constitutes around $90 \%$ of $\mathrm{SCH}$ cases on a population level $[6,7]$. However, since an array of factors has been shown to lead to transient abnormalities of serum TSH, investigation of raised TSH requires repeated measurements to establish a firm diagnosis. In particular, both healthy individuals and those with SCH have a circadian fluctuation in serum TSH concentration, with a nadir in the early afternoon and approximately $30 \%$ higher concentrations being present during the evening and night $[11,12]$. It has been demonstrated that the degree of variation in serum TSH was lower in SCH than in euthyroid controls, but rises as serum TSH concentrations increased [13]. Thus, several tests, ideally on blood drawn at the same time of day, are needed to establish a representative baseline for serum TSH [13]. In addition, measurement of serum $\mathrm{FT}_{4}$ is necessary to rule out overt hypothyroidism. Although the reference range for serum TSH in the general adult population is between 0.4 and $4.0 \mathrm{mU} / \mathrm{l}$, TSH concentrations in a healthy individual have a much smaller variation over time, approximating to a third of the reference interval [14]. This can be conceptualised as an individual's 'TSH setpoint'. Furthermore, follow-up of individuals using sequential TSH measurements over long periods of time shows a tendency for the TSH setpoint to increase a little with advancing age [15].

Aetiologically, most cases of persistent $\mathrm{SCH}$ are due to autoimmune thyroiditis (AIT); however, germline loss of function mutations in the TSH receptor account for a small proportion of cases [16]. In addition, transient elevations of TSH may occur in numerous circumstances, such as subacute or painless thyroiditis, following withdrawal of L-thyroxine, during recovery from a significant non-thyroidal illness and during treatment with various drugs (e.g. lithium, amiodarone) [17]. Furthermore, there is a widening of the reference range for serum TSH with increasing age, such that a mild TSH elevation (4.0-7.0 $\mathrm{mU} / \mathrm{l}$ ) in the elderly ( $>80$ years old) should be considered as a physiological adaptation to aging $[18,19]$. Measurement of bio-inactive isoforms of TSH may also explain higher values of TSH in some individuals [20]. Furthermore, the nocturnal peak of serum TSH may be delayed in night shift working, those with irregular sleep patterns, following vigorous exercise, and in mood disorders/depression. Since TSH levels correlate with BMI and markers of insulin resistance, serum TSH concentrations $>3.5$ $\mathrm{mU} / \mathrm{l}$ are also common in obesity [21]. Thus, identifica-

2013 ETA Guideline: Management of Subclinical Hypothyroidism tion of a transient increase of serum TSH is important and can be achieved by conducting repeated measurements of TSH. However, it is advantageous to wait for resolution of transient illness before repeating the serum TSH measurement; a 2- to 3-month interval from the initial finding of a raised TSH being reasonable.

\section{Thyroid Antibody Testing}

Since chronic AIT, which is the most common cause of $\mathrm{SCH}$, is marked by the presence of circulating antithyroid peroxidase antibodies (TPOAb), and/or antithyroglobulin antibodies ( $\mathrm{TgAb}$ ), measurement of serum thyroid autoantibodies will allow a firm aetiological diagnosis of AIT to be established. TPOAb are the most sensitive serological test for thyroid autoimmunity in $\mathrm{SCH}$ [22] and provide valuable information as to the rate of progression to overt hypothyroidism, which occurs most rapidly in patients with positive TPOAb (4.3\% per year) as compared to those with negative TPOAb $(2.6 \%$ per year) [23]. Serum concentrations of TPO-Ab may wane over time, but repeated antibody measurements do not enhance the monitoring of individual SCH patients [24]. Serum TPOAb determination is useful in patients with goitre or with other autoimmune diseases to diagnose AIT, as well as in patients with elevated serum TSH to identify the cause $[17,25]$.

\section{Imaging and Additional Testing Modalities}

A significant proportion of otherwise healthy people have asymptomatic chronic AIT, and $8 \%$ of women $(10 \%$ of women $>55$ years of age) and $3 \%$ of men have $\mathrm{SCH}$. In about $20 \%$ of SCH patients, TPOAb and/or TgAb antibodies are not detected. However, a hypoechoic or an inhomogeneous thyroid echo pattern at ultrasound (US) may be present before circulating autoantibodies and provide early evidence for thyroid autoimmunity [26]. While aspiration cytology is the most sensitive method for diagnosing AIT, a non-invasive examination by US also constitutes a reliable diagnostic tool [26]. Nevertheless, unless there are additional clinical indications, such as goitre, US is not routinely required in the management of SCH.

\section{Recommendations}

(1) There are two categories of $\mathrm{SCH}$ according to the elevation in serum TSH level: mildly increased TSH levels (4.0-10.0 $\mathrm{mU} / \mathrm{l})$, and more severely increased TSH value $(>10 \mathrm{mU} / \mathrm{l}) .2 \mathrm{~S}$

(2) An initial raised serum TSH with $\mathrm{FT}_{4}$ within reference range should be investigated with a repeat measure- 
ment of both serum $\mathrm{TSH}$ and $\mathrm{FT}_{4}$, along with thyroid peroxidase antibodies, preferably after a 2 - to 3 -month interval. $2 S$

(3) Individuals found to have positive antithyroid peroxidase or thyroglobulin antibodies, and/or those with a hypoechoic or an inhomogeneous echo pattern on thyroid US should have serum TSH measured. $2 \mathrm{~S}$

\section{Who to Treat/Who to Observe: Younger Adults (<65-70 Years)}

\section{Symptoms of Hypothyroidism}

Despite the clear biochemical pattern suggestive of mild hypothyroidism, few patients with $\mathrm{SCH}$ have typical hypothyroid symptoms. The only large study to systematically investigate symptoms in patients with overt and $\mathrm{SCH}$ as compared to euthyroid controls is the Colorado Thyroid Disease Prevalence Study [1]. This large questionnaire-based study in 25,862 subjects reported a small but significant difference in symptoms between euthyroid and subclinical hypothyroid patients. The main problems reported were drier skin, poorer memory, slower thinking, weaker muscles, greater tiredness, more muscle cramps, more feeling cold, deeper and hoarser voice, puffier eyes and more constipation in $\mathrm{SCH}$ [1]. The Tromsö study compared symptoms in 154 controls and $89 \mathrm{SCH}$ subjects with a TSH between 3.5 and $10.0 \mathrm{mU} / \mathrm{l}$ using a similar panel of questions [27]. Tiredness, but none of the other symptoms, was significantly different between the groups [27]. However, a meta-analysis of seven randomised studies (including 163 treated SCH patients) performed up to 2007 showed, on aggregate, no evidence for improvement of symptoms with L-thyroxine treatment of SCH [28]. The best evidence that intervention with L-thyroxine may impact on symptoms is provided by a randomised, cross-over study under either 100 $\mu \mathrm{g} L$-thyroxine or placebo in 100 subjects with a mean TSH of $6.6 \mathrm{mU} / \mathrm{l}$ [29]. Using the ThySC questionnaire, a 15-item questionnaire for hypothyroid symptoms, there was a significant improvement in tiredness during L-thyroxine treatment compared to placebo [29]. Other large studies that investigated symptoms in more elderly subjects did not find significant differences between symptoms in euthyroid controls and patients with SCH [30]. Therefore, most patients with SCH have few or no hypothyroid symptoms that are attributable to $\mathrm{SCH}$. However, if tiredness is present, then there is high-quality evidence from one study to suggest it may improve.

\section{Mood Disturbance/Mental Health}

A prospective, placebo-controlled, experimental study of L-thyroxine withdrawal in 19 women showed an impairment of declarative and working memory, as well as motor learning during SCH [31]. This was confirmed in two cross-sectional studies of 17 and $15 \mathrm{SCH}$ subjects showing impairment in memory function and verbal fluency $[32,33]$. Memory function was also improved in an open-label study of $17 \mathrm{SCH}$ patients when L-thyroxine was titrated to normalise TSH levels [34], and a similar, randomised Iranian study $(n=60)$ appears to confirm these data [35]. However, investigating subjects with a TSH between 3.5 and $10 \mathrm{mU} / \mathrm{l}$, Jorde et al. [27] could neither detect any differences in mood and cognitive function at baseline, nor any consistent response during carefully titrated L-thyroxine replacement. Similarly, two larger studies of elderly subjects ( $>65$ years; $n=164$ from Korea and $n=94$ from the UK) did not find any significant improvements from L-thyroxine using a battery of neurocognitive tests $[36,37]$. The inconsistent results of these different studies may be owing to differences in design, their relatively small size, the heterogeneous age groups recruited and large variety of neurocognitive tests used. There may also be important differences according to whether participants were preselected on the basis of their symptoms, or picked by biochemical screening of a population. Nevertheless, it seems probable that there is mild impairment of declarative memory, working memory, and mood in younger patients with $\mathrm{SCH}$ and that this improves with L-thyroxine therapy in a proportion of $\mathrm{SCH}$ patients. The available data do not suggest that the same benefits of treatment of SCH extend to subjects over the age of 65 years.

\section{Goitre and Thyroid Cancer}

$\mathrm{SCH}$ is modestly associated with goitre in adults, but the association is much stronger in children [38]. The Whickham Survey assessed goitre size by palpation and showed no relation between simple goitre and abnormal biochemical findings during the 20 years of follow-up [2]. Following hemithyroidectomy, a recent meta-analysis of 32 studies shows that the risk for the development of hypothyroidism is $22 \%$ [39].

Increasing TSH levels even within the normal range are associated with an increased risk of thyroid cancer [reviewed in 40,41]. This was first proposed in a cohort of 1,500 subjects by Boelaert et al. [42] when studying the frequency of malignancy in patients with palpable nodules by fine-needle aspiration and subsequently confirmed in stringent analyses by several groups [40, 41]. 
Studying 10,178 patients undergoing thyroid fine-needle aspiration with 942 thyroid nodules confirmed by histological evaluation, Fiore et al. [43] established a positive correlation between serum TSH levels and risk of thyroid malignancy. This relationship is discernible at all ages and also appears to be associated with the histological stage of the disease $[44,45]$. Correspondingly, the large study of 27,914 patients showed that treatment with L-thyroxine was associated with a lower risk of cancer [43]. These data suggest that $\mathrm{SCH}$, and even serum TSH variation within the normal range, may have a supportive role in the genesis and progression of thyroid cancer. It is therefore a possible but unproven inference that treatment of nodular goitre with L-thyroxine may protect against the development of thyroid carcinomas. However, given the low frequency of thyroid carcinoma and the slow development of these tumours, any prospective study to provide level 1 evidence to support this contention will be very difficult.

\section{Obesity and Diabetes Mellitus}

Experimentally induced acute weight gain has significant effects on $\mathrm{T}_{4}$ to $\mathrm{T}_{3}$ conversion [46]. A recent review of cohort studies of obese subjects suggests that serum TSH concentrations positively correlate with weight $[47$, 48]. Two longitudinal studies are of particular importance in supporting a significant positive association between increase in TSH levels and change in BMI $[49,50]$. One of these studies that stringently corrected for age, smoking habits and menopausal status indicated that for every unit increase in $\log \mathrm{TSH}$, there was $2.3 \mathrm{~kg}$ greater weight in females and $1.1 \mathrm{~kg}$ in men [50]. Conversely, substantial weight loss appears to be associated with a decrease in TSH levels as shown in several studies in children and adolescents, and also in adults following bariatric procedures such as gastric banding or gastric bypass surgery [51-54]. Currently there have been no randomised trials of the impact of L-thyroxine therapy in patients with obesity-related elevation of TSH serum levels. However, as observational studies are consistent in showing that TSH levels revert to normal upon weight reduction [51-54], a causal relation between $\mathrm{SCH}$ and obesity is not anticipated.

The prevalence of overt thyroid dysfunction in patients with type 1 diabetes mellitus is around $10 \%$, and lesser manifestations such as $\mathrm{SCH}$ and raised serum thyroid autoantibody concentrations are found in up to $30 \%$ of females [55-57]. This leads to the widespread recommendation that thyroid function should be monitored on a yearly basis in patients with type 1 diabetes mellitus [58, 59]. If autoimmune Addison's disease is present, the risk

2013 ETA Guideline: Management of

Subclinical Hypothyroidism of subclinical or overt hypothyroidism is as high as $50 \%$ and this combination of disorders frequently co-exists with type 1 diabetes (known as the autoimmune polyglandular syndrome type 2) [59, 60]. However, in the presence of untreated or inadequately replaced adrenal insufficiency, there is frequently an elevation in serum $\mathrm{TSH}$, and any judgment about the possibility of $\mathrm{SCH}$ should be delayed by at least 4 weeks from the institution of adequate steroid replacement in such patients [61].

Hypothyroidism is associated with a significant decrease in insulin sensitivity, most likely owing to a combination of effects including those on downregulation of plasma membrane glucose transporters and also direct effects on insulin secretion and clearance [62-65]. Therefore, overt hypothyroidism is, and by extension $\mathrm{SCH}$ may, be associated with insulin resistance and components of the metabolic syndrome [66]. In individuals with established type 2 diabetes mellitus, a change in glycaemic control could herald the onset of SCH or other thyroid problems [67]. In such individuals, where there is a contemporaneous worsening of glycaemic control with onset of $\mathrm{SCH}$, then a trial of L-thyroxine is warranted, with the success judged by the endpoint of improved glycaemic control [68].

\section{Dyslipidaemia}

Several observational studies investigated the relationship between $\mathrm{SCH}$ and dyslipidaemia with heterogeneous results [69-76]. A large epidemiologic study documented a positive relationship between serum TSH and dyslipidaemia, suggesting $\mathrm{SCH}$ as an intermediate state between euthyroidism and overt hypothyroidism in terms of lipid profile [1]. Interestingly, the EPIC-Norfolk prospective study found significantly increased concentrations of serum total cholesterol (TC), LDL cholesterol (LDLc) and triglyceride in SCH women only [72]. Similarly, in a large cross-sectional study an increase of $1.0 \mathrm{mU} / \mathrm{l}$ in serum TSH was associated with an average rise in TC values of $0.09 \mathrm{mM}$ in women [77], and a more recent report confirmed gender-related differences in the relationship between $\mathrm{SCH}$ and the lipid profile. In the latter study the impact of TSH elevation was substantially influenced by age, thus the effects of $\mathrm{SCH}$ on the serum lipid profile appears more pronounced in women and is also worse with increasing age [69]. Two meta-analyses showed an overall beneficial effect of L-thyroxine replacement on serum lipid levels in SCH patients [78, 79]. In addition, several small, randomised, controlled trials confirmed a significant reduction of both serum TC and LDLc values during L-thyroxine therapy [80-83]. In detail, Meier et al. [81] 
reported a reduction of serum TC by $0.24 \mathrm{mmol} / \mathrm{l}$ and of LDLc by $0.33 \mathrm{mmol} / \mathrm{l}$ after 12 months of L-thyroxine replacement. However, the effect was most pronounced in patients with baseline serum TSH values $>12 \mathrm{mU} / \mathrm{l}$. Similarly, Caraccio et al. [82] reported mean reductions in serum TC and LDLc concentrations of 0.47 and 0.41 $\mathrm{mmol} / \mathrm{l}$, respectively, in a strictly selected group of patients (mainly premenopausal women) with Hashimoto's thyroiditis and slightly elevated serum TSH level $(<10$ $\mathrm{mU} / \mathrm{l})$. Interestingly, in a subsequent randomised, controlled study from the same group [83], L-thyroxine replacement induced a significant improvement of both the lipoprotein profile and the carotid artery intima-media thickness: a widely recognised surrogate index of early atherosclerosis and CV events. Finally, in a recent randomised, double-blind, cross-over study, including 100 patients with stable $\mathrm{SCH}, \mathrm{L}$-thyroxine treatment significantly reduced serum TC and LDLc levels by 5.5 and $7.3 \%$, respectively [29]. Data from men in the Helsinki Heart Study have shown that a decrease of $7 \%$ in LDLc concentrations was associated with $15 \%$ reduction in the incidence of CHD [84], suggesting that these are potentially significant benefits.

\section{Cardiovascular System, Heart Failure and Ischaemic}

\section{Heart Disease}

$\mathrm{SCH}$ has been associated with functional cardiac abnormalities, such as left ventricular diastolic dysfunction, and reduced resting and exertional systolic function [8588]. Vascular abnormalities, such as increased vascular resistance, arterial stiffness, endothelial dysfunction, and atherosclerosis, have been also described [70, 83, 89-91]. Several interventional studies, some of which were randomised and placebo-controlled, showed that restoration of euthyroidism by L-thyroxine replacement therapy is able to improve most CV structural and functional surrogate markers $[29,83,85,86,89]$. However thus far, no randomised trial of L-thyroxine treatment for $\mathrm{SCH}$ has been carried out with the endpoints of hard CV outcomes. Although several surrogate markers for vascular disease appear to be favourably affected by L-thyroxine treatment in $\mathrm{SCH}$ patients, it is too early to be confident that intervention with L-thyroxine will lead to reversal of these vascular disease risks.

Some prospective studies evaluated the possible relationship between $\mathrm{SCH}$ and the risk of heart failure (HF) onset and progression in various clinical settings $[88,92$, 93]. The weight of evidence favours an increased risk of $\mathrm{HF}$ progression and events in $\mathrm{SCH}$ patients, although with different strength of association and, generally, for serum TSH values $>10.0 \mathrm{mU} / 1[94,95]$. In a large cohort of patients with previous CV risk, the persistence of elevated serum TSH value was associated with an increased risk of HF events over 3 years of follow-up [95]. In addition, $\mathrm{SCH}$ was independently associated with a greater likelihood of disease progression and a risk factor for increased mortality in hospitalised patients with incident HF [96]. Similarly, increased HF events were observed over a period of 12 years in $\mathrm{SCH}$ patients without previous $\mathrm{CV}$ risk [97]. Thus, $\mathrm{SCH}$ may act both as an independent risk factor for HF development and for progression to worsening HF [88]. Accordingly, a meta-analysis of six large, prospective studies on community-dwelling subjects confirmed that SCH patients with serum TSH $>10$ $\mathrm{mU} / \mathrm{l}$ had an age-independent increased rate of $\mathrm{HF}$ events [92]. However, a very recent prospective study failed to demonstrate any association between $\mathrm{SCH}$ and a 10-year risk of HF events, although a trend for increased incident HF after 8 years of follow-up was observed in the case of patients with TSH $>10 \mathrm{mU} / 1$ [94].

Several cohort studies have investigated the association between SCH and coronary heart disease (CHD) events and mortality with conflicting results [70, 71, 98103]. The initial analysis of the Whickham Survey [101], an early population-based study of community-dwelling individuals, found no association between autoimmune thyroid disease and CHD over 20 years of follow-up. However, a re-analysis of the data, looking specifically at individuals with SCH found an increase in CHD events and mortality, taking a more stringent definition of $\mathrm{SCH}$ and including subsequent L-thyroxine replacement as covariate [104]. In contrast, a survey of 3,233 communitydwelling older individuals did not show a significant difference in the prevalence of CHD, stroke, or peripheral artery disease between $\mathrm{SCH}$ patients and euthyroid people [99]. However, three meta-analyses of the most relevant prospective studies showed a positive association between SCH and CHD events and mortality [105-107]. Accordingly, a large meta-analysis, in which individual data on more than 50,000 participants from 11 prospective cohorts were collected, demonstrated that $\mathrm{CHD}$ mortality was increased in participants with serum TSH $>7.0$ $\mathrm{mU} / \mathrm{l}$ and that the risk of CHD events was significantly increased once serum was TSH $>10 \mathrm{mU} / 1$ [106]. Even if small clinical studies, some of which were randomised and placebo-controlled, showed that restoration of euthyroidism by L-thyroxine therapy improved surrogate indexes of cardiac and vascular function $[29,85,86]$, no large controlled trials have been performed to evaluate the effect of thyroid hormone replacement in preventing 
$\mathrm{CV}$ events and improving mortality. However, a recent real-life observational analysis of 4,500 SCH patients from the United Kingdom General Practitioner Research Database demonstrated that younger patients ( $<70$ years) who were started on L-thyroxine had lower CHD events over 8 years of follow-up [108]. This suggests at least that L-thyroxine treatment of $\mathrm{SCH}$ is safe in this patient group, and the results are consistent with a modest prognostic benefit from such therapy.

\section{Degree of TSH Elevation}

$\mathrm{SCH}$ is generally classified in two categories according to serum TSH level: mildly increased TSH levels (4.0-10.0 $\mathrm{mU} / \mathrm{l})$ and more severely increased serum TSH value $(>10$ $\mathrm{mU} / \mathrm{l})$ [109]. Most studies suggest that symptoms, manifestations and complications of SCH (including endothelial, lipid and CV alterations) are related to the degree of TSH elevation [105, 106, 110, 111]. A cross-sectional study on 1,101 individuals aged $>65$ years showed a significantly higher prevalence of $\mathrm{CHD}$ only in $\mathrm{SCH}$ patients with the highest serum TSH level (>10 mU/l) [100]. Similarly, in a large cohort of older people $(5,316$ subjects aged $70-82$ years), increased HF events were reported only in those with a serum TSH $>10 \mathrm{mU} / 1$ [95]. Moreover, as mentioned above, a large meta-analysis showed that the risk of CHD mortality and events increased with rising serum TSH concentrations, such that statistical significance was reached for CHD mortality only in patients with serum $\mathrm{TSH}>7 \mathrm{mU} / \mathrm{l}$ and for $\mathrm{CV}$ events once serum TSH was $>10$ $\mathrm{mU} / 1$ [106]. These results did not change after careful adjustment for age, gender and traditional CV risk factors. A more recent meta-analysis of six prospective studies of community-dwelling older individuals (mean age 70 years) confirmed that only patients with a serum TSH value $>10 \mathrm{mU} / \mathrm{l}$ had an increased rate of HF [92]. However, a large meta-analysis of 15 observational studies showed that only younger ( $<65$ years) SCH patients had an increased risk of CHD and CV mortality and an increased incidence (not prevalence) of CHD was found also in those with serum TSH value $<10 \mathrm{mU} / 1$ [107]. Similarly, a Danish cross-sectional study showed that $\mathrm{SCH}$ men younger than 50 years with serum TSH value $<10 \mathrm{mU} / \mathrm{l}$ had an increased risk of CV disease [112]. Moreover, increased CHD events were found over 10 years of followup in $\mathrm{SCH}$ men with mean age of 58.5 years and serum TSH $<10 \mathrm{mU} / \mathrm{l}$ [98] and over 20 years of follow-up in a similar mixed-gender cohort [71].

Despite some heterogeneity in the literature with regard to the relationship between $\mathrm{SCH}$ and $\mathrm{CV}$ disease, the available data suggest that the dominant risk of mild se-

2013 ETA Guideline: Management of

Subclinical Hypothyroidism rum TSH elevation $(<10 \mathrm{mU} / \mathrm{l})$ is in younger subjects (aged $<65$ years). As observational studies are subject to several limitations, clinical decisions based only on these data should be made with great caution. Nonetheless, while awaiting results from randomised, placebo-controlled trials, these results are useful to define a TSH threshold for considering L-thyroxine replacement based on clinical outcomes.

\section{Recommendations}

(4) In younger SCH patients ( $<65$ years; serum TSH $<10 \mathrm{mU} / \mathrm{l}$ ) with symptoms suggestive of hypothyroidism, a trial of L-thyroxine replacement therapy should be considered. $2 \mathrm{~W}$

(5) There is limited evidence for improvement in mental function with $\mathrm{LT}_{4}$ treatment of $\mathrm{SCH}$ in younger individuals. $3 \mathrm{~W}$

(6) Following hemithyroidectomy, persistent $\mathrm{SCH}$ should be treated with L-thyroxine to normalise TSH levels. $2 \mathrm{~S}$

(7) Patients with persistent SCH and diffuse or nodular goitre should be treated with L-thyroxine replacement with the aim of normalising serum TSH levels. $2 \mathrm{~W}$

(8) There is no evidence for a favourable effect of Lthyroxine therapy on body weight in obese subjects with serum TSH levels $<10 \mathrm{mU} / \mathrm{l}$ and normal $\mathrm{FT}_{4}$ concentrations. $3 \mathrm{~S}$

(9) In patients with type 1 diabetes mellitus, serum TSH should be monitored, once yearly. $3 \mathrm{~S}$

(10) In patients with type 2 diabetes mellitus and an unexplained change in glycaemic control, serum TSH and $\mathrm{FT}_{4}$ should be measured. $3 \mathrm{~W}$

(11) L-Thyroxine therapy of SCH is able to reduce the levels of both total and LDL cholesterol, although normalisation of serum lipids is seldom achieved. $2 \mathrm{~S}$

(12) The effect of L-thyroxine replacement on serum lipid concentrations is more pronounced in patients with pretreatment serum TSH value $>10 \mathrm{mU} / 1$. $1 \mathrm{~S}$

(13) Even in the absence of symptoms, replacement therapy with L-thyroxine is recommended for younger patients ( $<65$ years) with serum TSH $>10 \mathrm{mU} / \mathrm{l}$. $2 \mathrm{~S}$

\section{Outcomes in Older People}

The relationship between thyroid function and ageing was hypothesised many years ago, but its clinical impact has only been extensively evaluated for the last 20 years [93]. Interpretation of information in older individuals is complicated by the inconsistent use of age criteria in 
many studies. Thus, while there are clearly clinical and biological differences between younger and more elderly individuals with $\mathrm{SCH}$, it is impossible to draw a robust chronological demarcation, although many studies have seen differences between individuals $<60$ or 65 , and those $>70$ years of age. Thus, any decision about treatment of moderately old patients (e.g. 60-70 years) should include a specific evaluation of the pre-existent $\mathrm{CV}$ risk, degree of TSH elevation, comorbidity and frailty.

Large observational studies have shown that serum TSH distribution clearly shifts towards higher concentrations with age in iodine-replete populations; extreme longevity being associated with a further increase in TSH levels $[6,18,19,113]$. In contrast, a proportion of healthy centenarians from iodine-deficient regions have been shown to have a low or suppressed serum TSH. Thus, the use of age-specific reference ranges for serum TSH reduces the fraction of patients who are labelled with the diagnosis of $\mathrm{SCH}$, by $2 \%$ for patients $>75$ years and by $5 \%$ for those $>90[18,113]$. A 'physiological' age-dependent impairment of endothelial and cardiac function as well as lipid profile is well documented $[114,115]$ and the effective burden of mild thyroid failure on the CV system of older people, particularly in the 'oldest old' ( $>85$ years), is still to be firmly established [93].

\section{Heart Failure}

HF represents a common clinical condition, with increasing prevalence in the last decades of life. The changes to heart structure with ageing such as interstitial fibrosis and myocyte loss as well as cardiac hypertrophy and remodelling may contribute per se to the development of heart dysfunction (especially diastolic) [88, 114]. Mechanistically, SCH may worsen the age-related cardiac alterations resulting in an increased risk of HF progression and events, as shown by The Prospective Study of Pravastatin in the Elderly at Risk [95]. Similarly, an increased prevalence of HF events over a period of 12 years was described also in older $\mathrm{SCH}$ patients ( $>65$ years, with serum $\mathrm{TSH}>10 \mathrm{mU} / \mathrm{l}$ ) without previous CV risk [97]. A recent prospective study enrolling 4,863 participants aged $>65$ years at baseline showed no association between $\mathrm{SCH}$ and incident HF during 10 years of follow-up [94]. Nonetheless, a trend for an increased incident HF after 8 years of follow-up was still observed in the case of patients with $\mathrm{TSH}>10 \mathrm{mU} / 1$. Moreover, a recent pooled individual participant data analysis of six large prospective studies on community-dwelling subjects confirmed that $\mathrm{SCH}$ patients (TSH $>10 \mathrm{mU} / \mathrm{l}$ ) had an age-independent increased rate of $\mathrm{HF}$ events [92].

\section{Coronary Heart Disease}

A meta-analysis of ten pooled studies enrolling 14,449 participants found a pattern of moderate increased risk for $\mathrm{CHD}$ and mortality in $\mathrm{SCH}$ patients together with evidence for statistical heterogeneity. Indeed, the relationship between $\mathrm{SCH}$ and CHD depends on both the mean age of enrolled individuals ( $>65$ or $<65$ years) and the degree of serum TSH elevation $(>10$ or $<10 \mathrm{mU} / \mathrm{l})$ [105, 107]. Moreover, a recent prospective study enrolling 4,863 older participants showed no association between $\mathrm{SCH}$ and incident CHD or CV mortality after 10 years of follow-up [94]. Additional analyses stratified by degree of TSH elevation (4.5-6.9, 7.0-9.9, and 10.0-19.9 mU/l) confirmed no increase in $\mathrm{CV}$ risk, although a trend for an increased incidence of $\mathrm{CV}$ deaths in the entire $\mathrm{SCH}$ group after 6 years of follow-up was observed. In addition, almost one third of patients initially classified as having $\mathrm{SCH}$ were treated with thyroid hormone and this could have altered CV outcomes, calling into question the applicability of these data for treatment of older patients with SCH [94].

In contrast, a prospective study of 599 communitydwelling participants, followed up from age 85 to 89 years, showed a relationship between hypothyroidism and a lower mortality rate, which remained after adjustment for degree of TSH elevation, baseline disability and health status [116]. This study, however, focused on the 'oldest old' individuals and the results should be interpreted in the context of a single, unreproduced, observational study. Indeed, although the impact of $\mathrm{SCH}$ on $\mathrm{CHD}$ risk and mortality clearly presents an age-dependent feature, which seems to vanish in the last decades of life, a pooled individual patient data analysis of more than 50,000 individuals (including the latter cohort) demonstrated that the risk of CHD events increases significantly with higher levels of TSH ( $\mathrm{p}$ for trend $<0.001$ ), particularly in participants with serum TSH levels $>10.0 \mathrm{mU} / \mathrm{l}$ (hazard ratio $1.89,95 \%$ CI 1.28-2.80) [106]. In this setting, a very recent prospective analysis of data from the United Kingdom General Practitioner Research Database demonstrated that L-thyroxine replacement therapy was associated with fewer CHD events in middle-age and moderate-old $(<70$ years) $\mathrm{SCH}$ patients, but not in the oldest old population (mean age around 80 years) [108].

Overall, these observations raise the question of when (or whether) a high serum TSH should be treated in elderly patients, particularly in view of recent reports that longevity is associated with higher TSH levels in several groups of individuals, and mildly elevated TSH could somehow be beneficial in certain elderly patients [116, 
117]. A clear-cut distinction between subtle age-related change in thyroid physiology and slight TSH elevation $(<10 \mathrm{mU} / \mathrm{l})$ due to mild thyroid disease is not always apparent: a fuzzy line might link these two apparently distinct conditions, at least in the last decades of life.

The deleterious effect of SCH on CV events and mortality appears well established in young adults but is less evident in moderately older people $(<70-75$ years $)$ and could vanish in the oldest old ( $>80-85$ years). Appropriately powered RCT of L-thyroxine in $\mathrm{SCH}$ patients, examining hard $\mathrm{CV}$ endpoints in various classes of age, are clearly warranted with two such studies already in progress, recruiting over 65- and 80-year-old individuals [118, $119]$.

\section{Recommendations}

(14) Age-specific reference ranges for serum TSH should be considered in order to establish a diagnosis of $\mathrm{SCH}$ in older people. $2 \mathrm{~S}$

(15) The oldest old subjects ( $>80-85$ years) with elevated serum TSH $\leq 10 \mathrm{mU} / \mathrm{l}$ should be carefully followed with a wait-and-see strategy, generally avoiding hormonal treatment. $3 \mathrm{~S}$

\section{How to Treat?}

\section{Background}

Many patients with SCH do not need treatment, but if a decision is made to treat, then oral L-thyroxine is the treatment of choice. Randomised clinical trials of $\mathrm{SCH}$ patients have shown that L-thyroxine is effective in returning the biochemistry of a raised serum TSH into the reference range [27, 29, 120-123]. Doses of L-thyroxine used in these trials have varied substantially, but typical regimens have started with 25 or $50 \mu \mathrm{g}$ daily, with subsequent monthly or 2-monthly dose adjustment to maintain serum TSH within reference range. Using this approach, a study of $94>65$-year-old patients found that serum TSH could be normalised with a median dose of 50 $\mu \mathrm{g}$ (interquartile range 50-75 $\mu \mathrm{g}$ ) L-thyroxine [37]. Similarly, two smaller studies of younger $\mathrm{SCH}$ patients have found mean daily L-thyroxine doses of 68 and $71 \mu \mathrm{g}$ (range 50-125) were necessary to bring serum TSH into the reference range $[121,123]$. One study carefully titrated L-thyroxine doses in $36 \mathrm{SCH}$ patients to achieve serum TSH levels between 0.5 and $1.5 \mathrm{mU}$ and found that mean daily doses around $100 \mu \mathrm{g}$ (range 94-109) were necessary to achieve this [27]. Nevertheless, a large study that started all SCH participants on $100 \mu \mathrm{g}$-thyroxine daily found that only $10 \%$ were overtreated as judged by subnormal serum TSH (only $2 \%$ with elevated serum $\mathrm{FT}_{4}$ ) [29]. Thus, the evidence suggests that a daily dose of L-thyroxine between 50 and $100 \mu \mathrm{g}$ daily is adequate to normalise serum $\mathrm{TSH}$ in most $\mathrm{SCH}$ patients.

In most circumstances, it is most efficient and safe to start the patient directly on the appropriate full dose of L-thyroxine [124]. The exception to this is patients with established ischaemic heart disease in whom lower doses should be started, with subsequent stepwise dose increases. Typically in a patient with stable angina pectoris, a dose of $25 \mu \mathrm{g}$ L-thyroxine should be started and increased gradually by $25 \mu$ g every 2 or 3 weeks. Although a similar approach is often taken in elderly patients, particularly above the age of 70 years, a randomised trial showed that this was not necessary in older patients provided they have no heart disease [124].

For optimal absorption, L-thyroxine should be taken on an empty stomach. Studies show differing results with regard to the optimal time for its administration. One study of US patients showed optimal serum TSH control when L-thyroxine was taken in the fasting state, $60 \mathrm{~min}$ before breakfast [125]. However, a Dutch study showed that L-thyroxine taken at bedtime was superior to that taken $30 \mathrm{~min}$ before breakfast [126]. Several foods specifically impair L-thyroxine absorption, including milk (due to the calcium content), coffee, soya products and papaya $[127,128]$. Indeed, many medications including iron salts, calcium salts, antacids (including sucralfate, $\mathrm{H}_{2}$-receptor blockers and proton pump inhibitors), cholestyramine and raloxifene can interfere with L-thyroxine absorption [129]. Similarly, several gastrointestinal conditions can adversely affect L-thyroxine absorption, including atrophic gastritis/pernicious anaemia and coeliac sprue. Both impaired and improved L-thyroxine absorption are reported subsequent to different forms of bariatric surgery $[130,131]$. Individuals with these conditions are likely to need to take higher doses of L-thyroxine, or to take their medication with ascorbic acid or fruit juice.

While theoretical reasons might suggest a possible advantage from combining $\mathrm{T}_{4} / \mathrm{T}_{3}$ medication, trials using combined $\mathrm{T}_{4} / \mathrm{T}_{3}$ therapy have not shown conclusive benefits in overt hypothyroidism. Specifically, a meta-analysis of eleven studies enlisting more than 1,200 hypothyroid patients does not support any convincing benefit of the $\mathrm{T}_{4} / \mathrm{T}_{3}$ combined therapy [132]. With this background, and no specific data related to $\mathrm{SCH}$ patients, this treatment should be confined to clinical trials only and not recommended in practice for SCH patients [133]. 
Once started on L-thyroxine therapy, patients should have repeat serum TSH measurement after 8-12 weeks, and L-thyroxine dose adjusted, if necessary, to ensure that TSH has fallen into the reference range. In addition, if there was hypercholesterolaemia or other dyslipidaemia before L-thyroxine was commenced, then it is worthwhile to re-check the serum lipid profile to see whether there has been adequate improvement, or whether additional therapy for dyslipidaemia is necessary. At this stage, it is also worthwhile to re-evaluate the symptoms of hypothyroidism in those $\mathrm{SCH}$ individuals who were started on therapy for symptoms suggestive of hypothyroidism. Although most studies suggest little or no symptomatic benefit from treatment of SCH [27, 29, 120-123], if symptoms have improved, then lifelong treatment may be considered. If there has been no improvement in symptoms, or even some side effects perceived from the medication, then L-thyroxine may be stopped after a 3- to 6-month therapeutic trial.

\section{Recommendations}

(16) If the decision is to treat $\mathrm{SCH}$, then oral L-thyroxine, administered daily, is the treatment of choice. There is no evidence to support use of liothyronine $\left(\mathrm{T}_{3}\right)$ or combined L-thyroxine/liothyronine in the treatment of $\mathrm{SCH}$. $1 \mathrm{~S}$

(17) For patients without cardiac disease, a weight-related dose of L-thyroxine should be used, approximating to $1.5 \mu \mathrm{g} / \mathrm{kg}$ /day (e.g. 75 or $100 \mu \mathrm{g} /$ day for a woman, 100 or $125 \mu \mathrm{g}$ for a man). $1 \mathrm{~S}$

(18) For patients with cardiac disease and in the elderly, a small dose of L-thyroxine should be started, 25 or $50 \mu \mathrm{g}$ daily. The dose of $\mathrm{L}$-thyroxine should be increased by $25 \mu \mathrm{g} /$ day every 14-21 days until a full replacement dose is reached. $3 \mathrm{~S}$

(19) L-Thyroxine should be taken on an empty stomach, either first thing in the morning, an hour before food, or at bedtime, $2 \mathrm{~h}$ or more after the last food. Medications causing interference with L-thyroxine absorption (calcium and iron salts, proton pump inhibitors, etc.) should be avoided, or taken $4 \mathrm{~h}$ or more after L-thyroxine ingestion. $2 S$

(20) The serum TSH should be re-checked 2 months after starting L-thyroxine therapy, and dosage adjustments made accordingly. The aim for most adults should be to reach a stable serum TSH in the lower half of the reference range $(0.4-2.5 \mathrm{mU} / \mathrm{l}) .2 \mathrm{~W}$

(21) In the elderly, any treatment for $\mathrm{SCH}$ should be individualised, gradual and closely monitored. $2 \mathrm{~S}$
(22) For older patients ( $>70-75$ years), a higher treatment target for serum TSH (around $1-5 \mathrm{mU} / \mathrm{l}$ ) is acceptable. 3W

(23) For patients with mild SCH (serum TSH $<10$ $\mathrm{mU} / \mathrm{l}$ ) who have been started on L-thyroxine for symptoms attributed to $\mathrm{SCH}$, response to treatment should be reviewed 3 or 4 months after a serum TSH within the reference range is reached. If there is no improvement in symptoms, L-thyroxine therapy should generally be stopped. $3 \mathrm{~W}$

\section{Follow-Up of Untreated Patients}

A proportion of patients with $\mathrm{SCH}$ will progress to overt hypothyroidism, $5-8 \%$ per year depending on the degree of serum TSH elevation [2,134-136]. On the other hand, thyroid function may normalise in $6-35 \%$ of SCH patients depending on initial TSH levels, thyroid autoantibody status and length and frequency of follow-up $[134,137,138]$. Hence, in the majority, SCH remains stable.

Once $\mathrm{SCH}$ has been diagnosed then a repeat thyroid function test should be re-checked within 8-12 weeks along with thyroid autoantibodies. If thyroid function has normalised, then no further testing is required in those who are asymptomatic, have negative thyroid autoantibodies or do not have goitre. In those who have persistent $\mathrm{SCH}$, thyroid function should be tested 6 monthly at least for the first 2 years and then yearly thereafter $[3,24]$. This is to gauge the tempo of any tendency to progression and to detect consequent overt hypothyroidism.

\section{Recommendations}

(24) If thyroid function has normalised following an initially abnormal serum TSH result, then no further testing is required in those who are asymptomatic, have negative thyroid autoantibodies or do not have goitre. $2 \mathrm{~S}$

(25) In those who have persistent $\mathrm{SCH}$ but in whom treatment is not commenced, thyroid function should be tested 6 monthly for the first 2 years and then yearly thereafter. $2 \mathrm{~W}$

\section{Follow-Up of Treated Patients}

Commencing treatment with L-thyroxine in patients with $\mathrm{SCH}$ depends on individual patient circumstances but those with symptoms, goitre or progressive reduction in serum-free thyroid hormone concentrations should be considered for treatment, particularly in younger and middle-aged groups. The presence of positive thyroid autoantibodies additionally signifies compensated autoimmune thyroid failure, rather than hypofunctional TSH 
receptor mutation as the cause; however, there is no evidence to suggest that this patient group responds better to therapy. Several population-based studies of L-thyroxine-treated hypothyroid patients have shown that 40 $60 \%$ of individuals have biochemical evidence of underor over-replacement, indicating poor biochemical control $[1,8,139,140]$. This is potentially a significant health issue as there is evidence that both groups of patients have an excess of CV events and fractures [141, 142]. Therefore, once commenced on treatment, then thyroid function should be monitored 2-3 months later to ensure serum TSH is controlled and then at least annually thereafter. In younger patients with symptoms, the goal of treatment should be to alleviate their symptoms, aiming for a serum TSH in the lower half of the reference range
(0.3-2.5 mU/l) [17]. However, for older individuals, if treatment is decided upon, then more relaxed targets are acceptable, aiming for a serum TSH between 1.0 and 5.0 $\mathrm{mU} / \mathrm{l}$ in patients $>70$ years.

\section{Recommendation}

(26) Once patients with SCH are commenced on Lthyroxine treatment, then serum TSH should be monitored at least annually thereafter. $2 \mathrm{~S}$

\section{Disclosure Statement}

The authors have no conflicts of interest to disclose.

\section{References}

1 Canaris GJ, Manowitz NR, Mayor G, Ridgway EC: The Colorado thyroid disease prevalence study. Arch Intern Med 2000;160:526-534.

2 Vanderpump MP, Tunbridge WM, French JM, et al: The incidence of thyroid disorders in the community: a twenty-year follow-up of the Whickham Survey. Clin Endocrinol 1995; 43:55-68.

3 Surks MI, Ortiz E, Daniels GH, et al: Subclinical thyroid disease: scientific review and guidelines for diagnosis and management. JAMA 2004;29:228-238.

4 Guyatt GH, Oxman AD, Vist GE, et al, GRADE Working Group: GRADE: an emerging consensus on rating quality of evidence and strength of recommendations. BMJ 2008; 336:924-926.

5 Kunz R, Vigersky RA, Guyatt GH, Montori VM: A case for clarity, consistency, and helpfulness: state-of-the-art clinical practice guidelines in endocrinology using the grading of recommendations, assessment, development, and evaluation system. J Clin Endocrinol Metab 2008;93:666-673.

-6 Hollowell JG, Staehling NW, Flanders WD, et al: Serum TSH, $\mathrm{T}_{4}$, and thyroid antibodies in the United States population (1988 to 1994): National Health and Nutrition Examination Survey (NHANES III). J Clin Endocrinol Metab 2002;87:489-499.

7 Vanderpump MP, Tunbridge WM: Epidemiology and prevention of clinical and subclinical hypothyroidism. Thyroid 2002;12:839847.

8 Somwaru LL, Rariy CM, Arnold AM, Cappola AR: The natural history of subclinical hypothyroidism in the elderly: the cardiovascular health study. J Clin Endocrinol Metab 2012;97:1962-1969.
9 Evered DC, Ormston BJ, Smith PA, et al: Grades of hypothyroidism. Br Med J 1973; 5854:657-662.

10 Duntas LH: Subclinical hypothyroidism: a misnomer in search of a new name. Thyroid 2001;11:361-362.

11 Roelfsema F, Pereira AM, Veldhuis JD, et al: Thyrotropin secretion profiles are not different in men and women. J Clin Endocrinol Metab 2009;94:3964-3967.

12 Roelfsema F, Pereira AM, Adriaanse R, et al: Thyrotropin secretion in mild and severe primary hypothyroidism is distinguished by amplified burst mass and basal secretion with increased spikiness and approximate entropy. J Clin Endocrinol Metab 2010;95:928-934.

$\checkmark 13$ Karmisholt J, Andersen S, Laurberg P: Variation in thyroid function tests in patients with stable untreated subclinical hypothyroidism. Thyroid 2008; 18:303-308.

14 Andersen S, Pedersen KM, Bruun NH, Laurberg P: Narrow individual variations in serum $\mathrm{T}_{4}$ and $\mathrm{T}_{3}$ in normal subjects: a clue to the understanding of subclinical thyroid disease. J Clin Endocrinol Metab 2002;87:1068-1072.

15 Bremner AP, Feddema P, Leedman PJ, et al: Age-related changes in thyroid function: a longitudinal study of a community-based cohort. J Clin Endocrinol Metab 2012;97:15541562.

16 Alberti L, Proverbio MC, Costagliola S, et al: Germline mutations of TSH receptor gene as cause of nonautoimmune subclinical hypothyroidism. J Clin Endocrinol Metab 2002;87: 2549-2555.

17 Biondi B, Cooper DS: The clinical significance of subclinical thyroid dysfunction. Endocr Rev 2008;29:76-131.
8 Surks MI, Hollowell JG: Age-specific distribution of serum thyrotropin and antithyroid antibodies in the US population: implications for the prevalence of subclinical hypothyroidism. J Clin Endocrinol Metab 2007;92:45754582.

19 Atzmon G, Barzilai N, Hollowell JG, et al: Extreme longevity is associated with increased serum thyrotropin. J Clin Endocrinol Metab 2009;94:1251-1254.

20 Persani L, Borgato S, Romoli R, et al: Changes in the degree of sialylation of carbohydrate chains modify the biological properties of circulating thyrotropin isoforms in various physiological and pathological states. J Clin Endocrinol Metab 1998;83:2486-2492.

21 Åsvold BO, Bjøto T, Vatten LJ: Association of serum TSH with high body mass differs between smokers and never-smokers. J Clin Endocrinol Metab 2009;94:5023-5027.

22 Beever K, Bradbury J, Phillips D, et al: Highly sensitive assays of autoantibodies to thyroglobulin and to thyroid peroxidase. Clin Chem 1989;35:1949-1954.

23 Huber G, Staub JJ, Meier C, et al: Prospective study of the spontaneous course of subclinical hypothyroidism: prognostic value of thyrotropin, thyroid reserve, and thyroid antibodies. J Clin Endocrinol Metab 2002;87:32213226.

24 Karmisholt J, Andersen S, Laurberg P: Variation in thyroid function in subclinical hypothyroidism: importance of clinical follow-up and therapy. Eur J Endocrinol 2011;164:317323.

25 Garber JR, Cobin RH, Gharib H, et al: Clinical practice guidelines for hypothyroidism in adults: cosponsored by the American Association of Clinical Endocrinologists and the American Thyroid Association. Thyroid 2012;22:1200-1235. 
26 Pedersen OM, Aardal NP, Larssen TB, et al: The value of ultrasonography in predicting autoimmune thyroid disease. Thyroid 2000; 10:251-259.

27 Jorde R, Waterloo K, Storhaug H, et al: Neuropsychological function and symptoms in subjects with subclinical hypothyroidism and the effect of thyroxine treatment. J Clin Endocrinol Metab 2006;91:145-153.

- 28 Villar HC, Saconato H, Valente O, Atallah AN: Thyroid hormone replacement for subclinical hypothyroidism. Cochrane Database Syst Rev 2007;3:CD003419.

29 Razvi S, Ingoe L, Keeka G, et al: The beneficial effect of L-thyroxine on cardiovascular risk factors, endothelial function, and quality of life in subclinical hypothyroidism: randomized, crossover trial. J Clin Endocrinol Metab 2007;92:1715-1723.

-30 Joffe RT, Pearce EN, Hennessey JV, et al: Subclinical hypothyroidism, mood, and cognition in older adults: a review. Int J Geriatr Psychiatry 2013;28:111-118.

- 31 Samuels MH, Schuff KG, Carlson NE, et al: Health status, mood, and cognition in experimentally induced subclinical hypothyroidism. J Clin Endocrinol Metab 2007;25:25452551.

32 Baldini IM, Vita A, Mauri MC, et al: Psychopathological and cognitive features in subclinical hypothyroidism. Prog Neuropsychopharmacol Biol Psychiatry 1997;21:925-935.

-33 Del Ser Quijano T, Delgado C, Martinez Espinosa S, Vazquez C: Cognitive deficiency in mild hypothyroidism. Neurologia 2000;15: 193-198.

-34 Correia N, Mullally S, Cooke G, et al: Evidence for a specific defect in hippocampal memory in overt and subclinical hypothyroidism. J Clin Endocrinol Metab 2009;94 3789-3797.

- 35 Aghili R, Khamseh ME, Malek M, et al: Changes of subtests of Wechsler Memory Scale and cognitive function in subjects with subclinical hypothyroidism following treatment with levothyroxine. Arch Med Sci 2012; 8:1096-1101.

36 Park YJ, Lee EJ, Lee YJ: Subclinical hypothyroidism $(\mathrm{SCH})$ is not associated with metabolic derangement, cognitive impairment, depression or poor quality of life in elderly subjects. Arch Gerontol Geriatr 2010;50:e68e73.

37 Parle J, Roberts L, Wilson S, et al: A randomized controlled trial of the effect of thyroxine replacement on cognitive function in community-living elderly subjects with subclinical hypothyroidism: the Birmingham Elderly Thyroid Study. J Clin Endocrinol Metab 2010; 95:3623-3632.

38 Monzani A, Prodam F, Rapa A, et al: Endocrine disorders in childhood and adolescence. Natural history of subclinical hypothyroidism in children and adolescents and potential effects of replacement therapy: a review. Eur J Endocrinol 2012;168:R1-R11.
39 Verloop H, Louwerens M, Schoones JW, et al: Risk of hypothyroidism following hemithyroidectomy: systematic review and metaanalysis of prognostic studies. J Clin Endocrinol Metab 2012;97:2243-2255.

40 Boelaert K: The association between serum TSH concentration and thyroid cancer. Endocr Relat Cancer 2009;16:1065-1072.

$\checkmark 41$ Fiore E, Vitti P: Serum TSH and risk of papillary thyroid cancer in nodular thyroid disease. J Clin Endocrinol Metab 2012;97:1134-1145.

42 Boelaert K, Horacek J, Holder RL, et al: Serum thyrotropin concentration as a novel predictor of malignancy in thyroid nodules investigated by fine-needle aspiration. J Clin Endocrinol Metab 2006;91:4295-4301.

43 Fiore E, Rago T, Provenzale MA, et al: L-Thyroxine-treated patients with nodular goiter have lower serum TSH and lower frequency of papillary thyroid cancer: results of a crosssectional study on 27,914 patients. Endocr Relat Cancer 2010;17:231-239.

44 Haymart MR, Glinberg SL, Liu J, et al: Higher serum TSH in thyroid cancer patients occurs independent of age and correlates with extrathyroidal extension. Clin Endocrinol (Oxf) 2009;71:434-439.

45 Kim SS, Lee BJ, Lee JC, et al: Preoperative serum thyroid-stimulating hormone levels in well-differentiated thyroid carcinoma is a predictive factor for lateral lymph node metastasis as well as extrathyroidal extension in Korean patients: a single-center experience. Endocrine 2011;39:259-265.

46 Danforth E Jr, Horton ES, O’Connell M, et al: Dietary-induced alterations in thyroid hormone metabolism during overnutrition. J Clin Invest 1979;64:1336-1347.

47 De Moura Souza A, Sichieri R: Association between serum TSH concentration within the normal range and adiposity. Eur J Endocrinol 2011;165:11-15.

48 Kitahara CM, Platz EA, Ladenson PW, et al: Body fatness and markers of thyroid function among US men and women. PLoS One 2012; 7:e34979.

49 Nyrnes A, Jorde R, Sundsfjord J: Serum TSH is positively associated with BMI. Int J Obes (Lond) 2006;30:100-105.

50 Fox CS, Pencina MJ, D’Agostino RB, et al: Relations of thyroid function to body weight: cross-sectional and longitudinal observations in a community-based sample. Arch Intern Med 2008;168:587-592.

51 Wolters B, Lass N, Reinehr T: TSH and free triiodothyronine concentrations are associated with weight loss in a lifestyle intervention and weight regain afterwards in obese children. Eur J Endocrinol 2013;168:323-329.

52 Reinehr T, de Sousa G, Andler W: Hyperthyrotropinemia in obese children is reversible after weight loss and is not related to lipids. J Clin Endocrinol Metab 2006;91:3088-3091.
53 Dall'Asta C, Paganelli M, Morabito A, et al: Weight loss through gastric banding: effects on TSH and thyroid hormones in obese subjects with normal thyroid function. Obesity (Silver Spring) 2010;18:854-857.

54 Chikunguwo S, Brethauer S, Nirujogi V, et al: Influence of obesity and surgical weight loss on thyroid hormone levels. Surg Obes Relat Dis 2007;3:631-635.

55 Kadiyala R, Peter R, Okosieme OE: Thyroid dysfunction in patients with diabetes: clinical implications and screening strategies. Int J Clin Pract 2010;64:1130-1139.

56 Triolo TM, Armstrong TK, McFann K, et al: Additional autoimmune disease found in 33\% of patients at type 1 diabetes onset. Diabetes Care 2011;34:1211-1213.

57 Boelaert K, Newby PR, Simmonds MJ, et al: Prevalence and relative risk of other autoimmune diseases in subjects with autoimmune thyroid disease. Am J Med 2010;123:183.e1e9.

58 Perros P, McCrimmon RJ, Shaw G, Frier BM: Frequency of thyroid dysfunction in diabetic patients: value of annual screening. Diabet Med 1995;12:622-627.

59 Kahaly GJ: Polyglandular autoimmune syndrome type 2. Presse Med 2012;41:e663-e670.

60 Napier C, Pearce SH: Autoimmune Addison's disease. Presse Med 2012;41:e626-e635.

61 Stryker TD, Molitch ME: Reversible hyperthyrotropinemia, hyperthyroxinemia, and hyperprolactinemia due to adrenal insufficiency. Am J Med 1985;79:271-276.

-62 Dimitriadis G, Mitrou P, Lambadiari V, et al: Insulin action in adipose tissue and muscle in hypothyroidism. J Clin Endocrinol Metab 2006;91:4930-4937.

63 Roos A, Bakker SJ, Links TP, et al: Thyroid function is associated with components of the metabolic syndrome in euthyroid subjects. J Clin Endocrinol Metab 2007;92:491-496.

64 Maratou E, Hadjidakis DJ, Kollias A, et al: Studies of insulin resistance in patients with clinical and subclinical hypothyroidism. Eur J Endocrinol 2009;160:785-790.

65 Visser WE, Heemstra KA, Swagemakers SM et al: Physiological thyroid hormone levels regulate numerous skeletal muscle transcripts. J Clin Endocrinol Metab 2009;94: 3487-3496.

66 Stanická S, Vondra K, Pelikánová T, et al: Insulin sensitivity and counter-regulatory hormones in hypothyroidism and during thyroid hormone replacement therapy. Clin Chem Lab Med 2005;43:715-720.

67 Iwen A, Schroeder E, Brabant G: Thyroid hormones and the metabolic syndrome Eur J Thyroid, in press.

68 Skarulis MC, Celi FS, Mueller E, et al: Thyroid hormone induced brown adipose tissue and amelioration of diabetes in a patient with extreme insulin resistance. J Clin Endocrinol Metab 2010;95:256-262. 
69 Tognini S, Polini A, Pasqualetti G, et al: Age and gender substantially influence the relationship between thyroid status and the lipoprotein profile: results from a large cross-sectional study. Thyroid 2012;22:1096-1103.

-70 Hak AE, Pols HA, Visser TJ, et al: Subclinical hypothyroidism is an independent risk factor for atherosclerosis and myocardial infarction in elderly women: the Rotterdam Study. Ann Intern Med 2000;132:270-278.

71 Walsh JP, Bremner AP, Bulsara MK, et al: Subclinical thyroid dysfunction as a risk factor for cardiovascular disease. Arch Intern Med 2005;165:2467-2472.

-72 Boekholdt SM, Titan SM, Wiersinga WM, et al: Initial thyroid status and cardiovascular risk factors: the EPIC-Norfolk prospective population study. Clin Endocrinol (Oxf) 2010;72:404-410.

73 Cooper DS: Clinical practice. Subclinical hypothyroidism. N Engl J Med 2001;345:260265.

74 Klein I: Subclinical hypothyroidism - just a high serum thyrotropin concentration or something else? J Clin Endocrinol Metab. 2013;98:508-510.

75 Duntas LH, Brenta G: The effect of thyroid disorders on lipid levels and metabolism. Med Clin North Am 2012;96:269-281.

-76 Pearce EN: Update in lipid alterations in subclinical hypothyroidism. J Clin Endocrinol Metab 2012;97:326-333.

-77 Bindels AJ, Westendorp RG, Frölich M, et al: The prevalence of subclinical hypothyroidism at different total plasma cholesterol levels in middle-aged men and women: a need for case-finding? Clin Endocrinol 1999;50:217220.

-78 Danese MD, Ladenson PW, Meinert CL, Powe NR: Clinical review 115: effect of thyroxine therapy on serum lipoproteins in patients with mild thyroid failure: a quantitative review of the literature. J Clin Endocrinol Metab 2000;85:2993-3001.

79 Tanis BC, Westendorp GJ, Smelt HM: Effect of thyroid substitution on hypercholesterolaemia in patients with subclinical hypothyroidism: a re-analysis of intervention studies. Clin Endocrinol 1996;44:643-649.

80 Teixeira PF, Reuters VS, Ferreira MM, et al: Treatment of subclinical hypothyroidism reduces atherogenic lipid levels in a placebocontrolled double-blind clinical trial. Horm Metab Res 2008;40:50-55.

-81 Meier C, Staub JJ, Roth CB, et al: TSH-controlled L-thyroxine therapy reduces cholesterol levels and clinical symptoms in subclinical hypothyroidism: a double blind, placebocontrolled trial (Basel Thyroid Study). J Clin Endocrinol Metab 2001;86:4860-4866.

82 Caraccio N, Ferrannini E, Monzani F: Lipoprotein profile in subclinical hypothyroidism: response to levothyroxine replacement, a randomized placebo-controlled study. J Clin Endocrinol Metab 2002;87:1533-1538.
83 Monzani F, Caraccio N, Kozàkowà M, et al: Effect of levothyroxine replacement on lipid profile and intima-media thickness in subclinical hypothyroidism: a double-blind, placebo- controlled study. J Clin Endocrinol Metab 2004;89:2099-2106.

84 Manninen V, Elo MO, Frick MH, et al: Lipid alterations and decline in the incidence of coronary heart disease in the Helsinki Heart Study. JAMA 1988;260:641-651.

85 Biondi B, Fazio S, Palmieri EA, et al: Left ventricular diastolic dysfunction in patients with subclinical hypothyroidism. J Clin Endocrinol Metab 1999;84:2064-2067.

86 Monzani F, Di Bello V, Caraccio N, et al: Effect of L-thyroxine on cardiac function and structure in subclinical hypothyroidism: a double-blind, placebo-controlled study. J Clin Endocrinol Metab 2001;86:11101115.

87 Yazici M, Gorgulu S, Sertbas Y, et al: Effects of thyroxin therapy on cardiac function in patients with subclinical hypothyroidism: index of myocardial performance in the evaluation of left ventricular function. Int J Cardiol 2004; 95:135-143.

88 Biondi B: Mechanisms in endocrinology: heart failure and thyroid dysfunction. Eur J Endocrinol 2012;167:609-618.

89 Taddei S, Caraccio N, Virdis A, et al: Impaired endothelium-dependent vasodilatation in subclinical hypothyroidism: beneficial effect of L-thyroxine therapy. J Clin Endocrinol Metab 2003;88:3731-3737.

90 Shakoor SK, Aldibbiat A, Ingoe LE, et al: Endothelial progenitor cells in subclinical hypothyroidism: the effect of thyroid hormone replacement therapy. J Clin Endocrinol Metab 2010;95:319-322.

91 Cabral MD, Teixeira PF, Silva NA, et al: Normal flow-mediated vasodilatation of the brachial artery and carotid artery intima-media thickness in subclinical hypothyroidism. Braz J Med Biol Res 2009;42:426-432.

92 Gencer B, Collet TH, Virgini V, et al: Subclinical thyroid dysfunction and the risk of heart failure events: an individual participant data analysis from six prospective cohorts. Circulation 2012;126:1040-1049.

93 Pasqualetti G, Tognini S, Polini A, et al: Is subclinical hypothyroidism a cardiovascular risk factor in the elderly? J Clin Endocrinol Metab 2013;98:2256-2266.

94 Hyland KA, Arnold AM, Lee JS, Cappola AR: Persistent subclinical hypothyroidism and cardiovascular risk in the elderly: the Cardiovascular Health Study. J Clin Endocrinol Metab 2013;98:533-540.

95 Nanchen D, Gussekloo J, Westendorp RG, et al, PROSPER Group: Subclinical thyroid dysfunction and the risk of heart failure in older persons at high cardiovascular risk. J Clin Endocrinol Metab 2012;97:852-861.

96 Iervasi G, Molinaro S, Landi P, et al: Association between increased mortality and mild thyroid dysfunction in cardiac patients. Arch Intern Med 2007;167:1526-1532.
-97 Rodondi N, Bauer DC, Cappola AR, et al: Subclinical thyroid dysfunction, cardiac function, and the risk of heart failure. The Cardiovascular Health Study. J Am Coll Cardiol 2008;52:1152-1159.

-98 Imaizumi M, Akahoshi M, Ichimaru S, et al: Risk for ischemic heart disease and all-cause mortality in subclinical hypothyroidism. J Clin Endocrinol Metab 2004;89:3365-3370.

99 Cappola AR, Fried LP, Arnold AM, et al: Thyroid status, cardiovascular risk, and mortality in older adults. JAMA 2006;295: 1033-1041.

100 Lindeman RD, Romero LJ, Schade DS, et al: Impact of subclinical hypothyroidism on serum total homocysteine concentrations, the prevalence of coronary heart disease (CHD), and CHD risk factors in the New Mexico Elder Health Survey. Thyroid 2003;13:595-600.

101 Vanderpump MP, Tunbridge WM, French $\mathrm{JM}$, et al: The development of ischemic heart disease in relation to autoimmune thyroid disease in a 20-year follow-up study of an English community. Thyroid 1996;6:155160.

102 Parle JV, Maisonneuve P, Sheppard MC, et al: Prediction of all-cause and cardiovascular mortality in elderly people from one low serum thyrotropin result: a 10-year cohort study. Lancet 2001;358:861-865.

103 Tseng FY, Lin WY, Lin CC, et al: Subclinical hypothyroidism is associated with increased risk for all-cause and cardiovascular mortality in adults. J Am Coll Cardiol 2012;60: 730-737.

104 Razvi S, Weaver JU, Vanderpump MP, Pearce SHS: The incidence of ischemic heart disease and mortality in people with subclinical hypothyroidism: re-analysis of the Whickham Survey cohort. J Clin Endocrinol Metab 2010;95:1734-1740.

105 Ochs N, Auer R, Bauer DC, et al: Meta-analysis: subclinical thyroid dysfunction and the risk for coronary heart disease and mortality. Ann Intern Med 2008;148:832-845.

106 Rodondi N, den Elzen WP, Bauer DC, et al, Thyroid Studies Collaboration: Subclinical hypothyroidism and the risk of coronary heart disease and mortality. JAMA 2010; 304:1365-1374

107 Razvi S, Shakoor A, Weaver JU, et al: The influence of age on ischemic heart disease and mortality in subclinical hypothyroidism - a meta-analysis. J Clin Endocrinol Metab 2008;93:2998-3007.

108 Razvi S, Weaver JU, Butler TJ, Pearce SHS: Levothyroxine treatment of subclinical hypothyroidism, fatal and nonfatal cardiovascular events and mortality. Arch Intern Med 2012;172:811-818.

109 Gharib H, Tuttle RM, Baskin HJ, et al: Subclinical thyroid dysfunction: a joint statement on management from the American Association of Clinical Endocrinologists, the American Thyroid Association, and the Endocrine Society. J Clin Endocrinol Metab 2005;90:581-585. 
110 Singh S, Duggal J, Molnar J, et al: Impact of subclinical thyroid disorders on coronary heart disease, cardiovascular and all-cause mortality: a meta-analysis. Int J Cardiol 2008;125:41-48.

-111 Haentjens P, Van Meerhaeghe A, Poppe K, Velkeniers B: Subclinical thyroid dysfunction and mortality: an estimate of relative and absolute excess all-cause mortality based on time-to-event data from cohort studies. Eur J Endocrinol 2008;159:329341.

112 Kvetny J, Heldgaard PE, Bladbjerg EM, Gram J: Subclinical hypothyroidism is associated with a low-grade inflammation, increased triglyceride levels and predicts cardiovascular disease in males below 50 years. Clin Endocrinol 2004;61:232-238.

113 Bremner AP, Feddema P, Leedman PJ, et al: Age-related changes in thyroid function: a longitudinal study of a community-based cohort. J Clin Endocrinol Metab 2012;97: 1554-1562.

-114 Strait JB, Lakatta EG: Aging-associated cardiovascular changes and their relationship to heart failure. Heart Fail Clin 2012;8:143164.

115 Tetè S, Tripodi D, Rosati M, et al: Endothelial cells, cholesterol, cytokines, and aging. Int J Immunopathol Pharmacol 2012;25: 355-363.

116 Gussekloo J, van Exel E, Craen AJM, et al: Thyroid status, disability and cognitive function, and survival in old age. JAMA 2004;292:2591-2599.

-117 Rozing MP, Houwing-Duistermaat JJ, Slagboom PE, et al: Familial longevity is associated with decreased thyroid function. J Clin Endocrinol Metab 2010;95:4979-4984.

118 TRUST study website: www.trustthyroidtrial.com.

-119 Mooijaart SP, IEMO 80-plus Thyroid Trial Collaboration: Subclinical thyroid disorders. Lancet 2012;380:335.

120 Meier C, Staub JJ, Roth CB, et al: TSH-controlled L-thyroxine therapy reduces cholesterol levels and clinical symptoms in subclinical hypothyroidism: a double blind, placebo-controlled trial (Basel Thyroid Study). J Clin Endocrinol Metab 2001;86: 4860-4866.
121 Cooper DS, Halpern R, Wood LC, et al: LThyroxine therapy in subclinical hypothyroidism. A double-blind, placebo-controlled trial. Ann Intern Med 1984;101:1824.

122 Nyström E, Caidahl K, Fager G, et al: A double-blind cross-over 12-month study of Lthyroxine treatment of women with 'subclinical' hypothyroidism. Clin Endocrinol (Oxf) 1988;29:63-75.

123 Jaeschke R, Guyatt G, Gerstein H, et al: Does treatment with L-thyroxine influence health status in middle-aged and older adults with subclinical hypothyroidism? J Gen Intern Med 1996;11:744-749.

124 Roos A, Linn-Rasker SP, van Domburg RT, et al: The starting dose of levothyroxine in primary hypothyroidism treatment: a prospective, randomized, double-blind trial. Arch Intern Med 2005;165:1714-1720.

125 Bach-Huynh TG, Nayak B, Loh J, et al: Timing of levothyroxine administration affects serum thyrotropin concentration. J Clin Endocrinol Metab 2009;94:3905-3912.

126 Bolk N, Visser TJ, Nijman J, et al: Effects of evening vs. morning levothyroxine intake: a randomized double-blind crossover trial. Arch Intern Med 2010;170:1996-2003.

127 Benvenga S, Bartolone L, Pappalardo MA, et al: Altered intestinal absorption of L-thyroxine caused by coffee. Thyroid 2008;18:293301.

128 Bell DS, Ovalle F: Use of soy protein supplement and resultant need for increased dose of levothyroxine. Endocr Pract 2001;7:193194.

129 Liwanpo L, Hershman JM: Conditions and drugs interfering with thyroxine absorption. Best Pract Res Clin Endocrinol Metab 2009;23:781-792

130 Bevan JS, Munro JF: Thyroxine malabsorption following intestinal bypass surgery. Int J Obes 1986;10:245-246.

131 Gkotsina M, Michalaki M, Mamali I, et al: Improved levothyroxine pharmacokinetics after bariatric surgery. Thyroid 2013;23: 414-419.

132 Grozinsky-Glasberg S, Fraser A, Nahshoni $\mathrm{E}$, et al: Thyroxine-triiodothyronine combination therapy versus thyroxine monotherapy for clinical hypothyroidism: metaanalysis of randomized controlled trials. J Clin Endocrinol Metab 2006;91:2592-2599.
33 Wiersinga WM, Duntas L, Fadeyev V, et al: 2012 ETA Guidelines: the use of $\mathrm{L}-\mathrm{T}_{4}+\mathrm{L}-\mathrm{T}_{3}$ in the treatment of hypothyroidism. Eur Thyroid J 2012;1:55-71.

134 Parle JV, Franklyn JA, Cross KW, et al: Prevalence and follow-up of abnormal thyrotrophin (TSH) concentrations in the elderly in the United Kingdom. Clin Endocrinol (Oxf) 1991;34:77-83.

135 Kabadi UM: 'Subclinical hypothyroidism'. Natural course of the syndrome during a prolonged follow-up study. Arch Intern Med 1993;153:957-961.

136 Huber G, Staub JJ, Meier C, et al: Prospective study of the spontaneous course of subclinical hypothyroidism: prognostic value of thyrotropin, thyroid reserve, and thyroid antibodies. J Clin Endocrinol Metab 2002; 87:3221-3226.

137 Diez JJ, Iglesias P: Spontaneous subclinical hypothyroidism in patients older than 55 years: an analysis of natural course and risk factors for the development of overt thyroid failure. J Clin Endocrinol Metab 2004;89: 4890-4897.

138 Meyerovitch J, Rotman-Pikielny P, Sherf M, et al: Serum thyrotropin measurements in the community: five-year follow-up in a large network of primary care physicians. Arch Intern Med 2007;167:1533-1538.

139 Parle JV, Franklyn JA, Cross KW, et al: Thyroxine prescription in the community: serum thyroid-stimulating hormone level assays as an indicator of undertreatment or overtreatment. Br J Gen Pract 1993;43:107109.

140 Okosieme OE, Belludi G, Spittle K, et al: Adequacy of thyroid hormone replacement in a general population. QJM 2011;104:395401 .

141 Flynn RW, Bonellie SR, Jung RT, et al: Serum thyroid-stimulating hormone concentration and morbidity from cardiovascular disease and fractures in patients on longterm thyroxine therapy. J Clin Endocrinol Metab 2010;95:186-193.

142 Sawin CT, Geller A, Wolf PA: Low serum thyroid-stimulating hormone concentrations as a risk factor for atrial fibrillation in older persons. N Engl J Med 1994;331: 1249-1252. 